\title{
L/A MADRE NO EXISTE: LACAN, MEDEA Y LA POSICIÓN FEMENINA DE LA "VERDADERA" MUJER
}

\author{
Norman Marín Calderón ${ }^{1}$ \\ Universidad de Costa Rica, Costa Rica \\ normanmarin@ hotmail.com \\ ORCID: 0000-0001-5632-4598
}

Doi: 10.17533/udea.affs.v16n31a07

\section{Resumen}

Este ensayo propone una lectura psicoanalítica de la Medea de Eurípides. Lacan sostiene que Medea es una "verdadera mujer" porque su acto privilegia la condición de mujer antes que la de madre. En este sentido, Medea de Eurípides es la tragedia de la feminidad ideal. Colocada en un más allá de la maternidad, ella se convierte en el paradigma de la mujer que

sacrifica el tener (sus hijos) por el ser (mujer). Finalmente, en este artículo, se analiza la importancia del nombre propio para luego arribar a las distintas posiciones femeninas que Medea adopta a lo largo de la tragedia.

Palabras claves: Medea, Eurípides, Lacan, mujer, madre, nombre propio, amor.

\section{MOTHER DOES NOT EXIST: LACAN, MEDEA, AND FEMININE POSITION OF THE "TRUE" WOMAN.}

\section{Abstract}

This paper proposes a psychoanalytic argues that Medea is a "true woman" reading of Euripides' Medea. Lacan because her act favors the woman

1 Psicoanalista y filólogo. Doctor en Letras, Purdue University (Estados Unidos de Norteamérica). Magíster en Psicoanálisis, Instituto de Altos Estudios Universitarios de la Universidad de León (España) y Centro de Investigaciones y Estudios Psicoanalíticos de la Fundación Mexicana de Psicoanálisis. Magíster en Literatura Inglesa, Universidad de Costa Rica. 
condition over the mother one. In this sense, Euripides' Medea is the tragedy of the ideal femininity. Placed beyond maternity, she becomes the paradigm of the woman who sacrifices having (her children) for being (woman). Finally, the paper analyses the importance of the proper name to arrive to the different feminine positions adopted by Medea throughout the tragedy.

Keywords: Medea, Euripides, Lacan, woman, mother, proper name, love.

\section{LA MĖRE N'EXISTE PAS : LACAN, MÉDÉE ET LA POSITION FÉMININE DE LA « VRAIE » FEMME}

\section{Résumé}

Ce texte propose une lecture psy- sacrifiant l'avoir (des enfants) à l'être chanalytique de Médée d'Euripide. (femme). Finalement, cet article anaLacan affirme que Médée est une " lyse l'importance du nom propre vraie femme » car son acte privilégie pour aborder ensuite les différentes la condition de femme sur celle de positions féminines adoptées par Mémère. En ce sens, Médée d'Euripide dée tout au long de la tragédie. est la tragédie de la féminité idéale. Positionnée au-delà de la maternité, Mots-clés : Médée, Euripide, Lacan, elle devient le paradigme de la femme femme, mère, nom propre, amour. 
... I will kill thee/ And love thee after.

Shakespeare, Othello (Acto 5, Escena 2).

\section{Introducción}

De acuerdo con la teoría psicoanalítica desarrollada por Jacques Lacan, la Medea de Eurípides sintetiza el ser de la "verdadera mujer" porque ejemplifica el antagonismo entre el lugar de "madre" y el de "esposa". Una lectura lacaniana de esta obra permitirá atisbar la verdad de la protagonista a partir del nombre propio y este en relación con su maternidad, tan cuestionada, en la que prima la reivindicación femenina del amor erótico. Antes que nada, una madre es primero la mujer de un partenaire. Para respaldar la tesis lacaniana de la "verdadera mujer" nos centraremos primero en algunas elaboraciones freudianas sobre la feminidad para luego arribar a las propuestas lacanianas de la no-universalidad de la mujer, el goce femenino, la lógica del no-todo y los estragos del amor que para este psicoanalista siempre refieren al vacío y la imposibilidad, ejes que sintetizan el famoso aforismo lacaniano de la definición del amor: "amar es dar lo que no se tiene a quien no es".

\section{La tragedia de Eurípides}

Medea es considerada la obra maestra de Eurípides (480-406 a.e.c), la cual fue representada alrededor del año 430, y que a su vez formaba parte de la tetralogía dramática Filictotes, Dictis y Los recolectores. De todas las versiones clásicas del mito griego, verbigracia la de Ovidio o la de Séneca, la de Eurípides es posiblemente la más conocida debido al filicidio que, por celos, comete la protagonista. Por ejemplo, si Yocasta encarna el acto turbador de esa madre que hace suyo a su propio hijo por la vía sexual, la Medea de Eurípides representa otra versión nefasta de la maternidad: es la mujer que asesina a sus retoños por celos hacia su marido. Entonces se podría afirmar que por la madre se vive, pero también, por ella, se puede morir. 
La historia de Medea da inicio con la aparición del ambicioso Jasón, quien emprende una expedición con los argonautas. Por mandato de Pelias, rey de Yolco, Jasón es enviado a la Cólquide con el propósito de adueñarse del vellocino de oro, condición necesaria para convertirse en el sucesor del rey. El vellocino pertenecía a Eetes, rey de la Cólquide y padre de Medea. Ante la gran dificultad que tiene que sortear Jasón para apoderarse del vellocino, Medea, enamorada de este y empleando sus dotes de maga, ayuda al joven insaciable a obtener el codiciado botín. Una vez extraído el trofeo, Medea huye con Jasón quien le había prometido matrimonio a cambio de dicha ayuda. Para retrasar la persecución y castigo de su padre enfurecido, Medea -atrevida e inmoral- asesina a su hermano Apsirto, a quien descuartiza y lanza al mar, esto con el fin de que Eetes se demore recogiendo los pedazos del cuerpo de su primogénito. Es en este punto donde Eurípides empieza su tragedia. La Nodriza lo describe así:

Ojalá el casco de Argo no hubiera volado

hacia la tierra de Cólquide, las oscuras rocas Simplégades,

ni en los valles boscosos del Pelión hubiera caído nunca

el pino después de ser cortado, ni hubieran colocado para remar las manos

de los mejores hombres, quienes fueron a buscar el vellocino de oro para Pelias. Pues mi señora Medea no

habría navegado hacia las torres de la tierra de Yolco golpeada en el alma por la pasión de Jasón. (Eurípides, 2010, vv. $1-8)$.

Después de esto, Jasón y Medea se exilian en Corinto donde viven felizmente casados por diez años y procrean dos hijos. Luego de este tiempo, Creonte, rey de Corinto, sin importarle su condición de casado, le propone a Jasón desposar a su hija Glauce (también conocida con el nombre de Creúsa), quien no duda en hacerlo: nuevamente Jasón ostenta su ambición desmesurada. Pero Medea, celosa y mancillada, y aprovechándose de su condición de hechicera, impregnó de 
veneno un vestido y unas joyas que envía con sus propios hijos como obsequio a la nueva esposa de Jasón. Al ponérselos, Glauce muere envenenada al contacto de las ropas. Creonte, su padre, en un afán desesperado por auxiliarla, muere de la misma manera. Insatisfecha con todo el mal producido, Medea asesina a sus propios hijos, huyendo a la tierra de Egeo quien le ofrece asilo. Al liquidar a su futura esposa y a sus dos hijos, Medea da muerte a Jasón sin matarlo, dejándolo solo, desgraciado e indefenso. Sucintamente expuesto, así es como concluye la tragedia de Eurípides, Medea.

\section{Medea o la significancia del nombre propio}

Un primer abordaje posible de la tragedia de Eurípides requiere del análisis del nombre propio de Medea. Para el psicoanálisis, el nombre propio es el trazo significante que representa la singularidad del ser del sujeto. En su Seminario 9, La identificación (1961-1962), Lacan afirma que el nombre propio corresponde a ese trazo único, “(...) a esa huella que de un lenguaje a otro no se traduce, puesto que se transpone o se transfiere, y está allí justamente su característica: me llamo Lacan en todas las lenguas" (clase del 10 de enero de 1962, inédito). El nombre propio corresponde entonces al "rasgo unario" intraducible, a un significante impar y puro que hace del individuo un ser único e irremplazable: el nombre es lo que no se traduce y se repite.

Por su parte, Tesone (2009), siguiendo las elucubraciones de Ouaknin y Rotnemer, sostiene que todo nombre propio conlleva tres funciones esenciales, a saber: de identificación, de filiación y de proyecto. La primera función, la de identificación, indica que el nombre propio es una marca específica de determinación social, la cual designa al sujeto como un individuo único entre muchos. Segundo, con respecto a la filiación, el nombre de pila sugiere que este es una donación tanto imaginaria como simbólica que los padres imprimen sobre el hijo. Es un don que lo inserta en la continuidad de una filiación, inscribiéndolo en los linajes parentales: "la asignación al niño de un nombre sanciona el hecho de que la filiación no es un hecho biológico sino simbólico" (Tesone, 2009, p. 15). Finalmente, el nombre propio se caracteriza por ser un "proyecto". Junto con la identificación y los 
deseos de los padres, el nombre de pila se establece conforme a una historia previa y una significación específica: el nombre significa algo para alguien. Citando a El pensamiento salvaje de Levi-Strauss, Tesone vuelve a proponer que "no se nombra nunca, [sino] que se clasifica al otro si el nombre que se le da es en función de sus características" $(2009$, p. 71$)$. Y en cuanto a esta función de "proyecto" es que se puede abordar el nombre de Medea.

A este respecto, en el Crátilo de Platón, Sócrates le insiste a Hermógenes que el nombre propio es la imitación de la cosa a la que se nombra, es decir, que para los objetos de este mundo siempre existen "nombres que son naturales a las cosas, y que no es dado a todo el mundo ser artífice de nombres; y que sólo es competente el que sabe qué nombre es naturalmente propio a cada cosa" (2017/1966, p. 10). Lo que propone Sócrates aquí es que existe una relación intrínseca entre la cosa y su nombre; o como lo expresara Borges en su poesía: "Si (como el griego afirma en el Cratilo)/ el nombre es arquetipo de la cosa, / en las letras de rosa está la rosa/ y todo el Nilo en la palabra Nilo" (2015, p. 193). Por lo tanto, para Borges el nombre de pila es un duplicado entre la cosa y el nombre, es decir, corresponde a la esencia que surge al combinar "las letras y las sílabas" (2015, p. 193). Así, el Crátilo de Platón insiste en que cada nombre propio dice algo de la cosa a la que se refiere, y basta "que la esencia de la cosa domine en el nombre, y que se manifieste en él" (2017/1966, p. 13). En este sentido, los nombres propios son palabras que no significan, sino que refieren. Así, este deambular por el Crátilo será de suma importancia para analizar la significación del nombre propio de Medea.

En primer lugar, para la mayoría de los estudiosos, el nombre

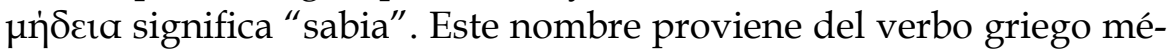

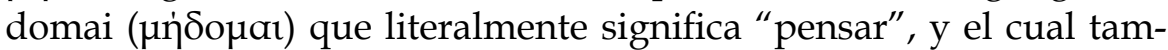
bién estar relacionado con acciones tales como "tramar, planear e inventar", que califican de manera cabal los artificios de la protagonista. Es en este sentido que el nombre propio de Medea alude a sus dotes de maga y pitonisa. Recuérdese que es gracias a estas pericias de la hechicería que Medea consigue el vellocino de oro para Jasón, y es por ellas que también logra envenenar la ropa que le regala a la nueva esposa de este. Esta suerte de artilugio de la sabiduría y el pensamiento es el que también le permite a Medea convencer al rey Creonte que 
le conceda quedarse un día más en Corinto para finiquitar su plan, cuando ya este la había expulsado de su reino. La misma Medea dice de sí misma: "Pues, siendo sabia, a unos soy odiosa, a otros indolente, a otros de carácter contrario" (vv. 303-304). Esto implica que la sabiduría de Medea reside en su capacidad de seducción y convencimiento, a nivel del saber, en cierta téchne ( $\tau \dot{\varepsilon} \chi \vee \eta)$, por cuanto alude a un conocimiento que rebasa todo entendimiento: “Lo mejor es la vía directa en la que hemos llegado a ser sabias por excelencia, apresarlos con mis venenos" (vv. 384-385), exclama Medea cuando mata a Glauce y su padre.

Otros eruditos sostienen que Medea también refiere al pronombre indefinido medeís ( $\mu$ $\delta$ sis) que literalmente significa "nadie". Esto estaría relacionado a la condición de expatriada y extranjera de nuestra protagonista, a su condición de "ninguna", quien primero es obligada a salir de su propia patria para huir con Jasón y luego es expulsada de Corinto a la tierra de Egeo. De igual manera, en relación a esto afirma Verónica Peinado Vázquez (2011) que “Medea era una extranjera, por lo tanto sin ningún valor en la sociedad corintia; [y también] era mujer, condición en general ínfima en el mundo griego, y dentro de esa condición ni siquiera era considerada esposa legítima de Jasón" (s.p.). Es decir, Medea era "nadie" pues no gozaba de ningún privilegio ni como mujer ni como ciudadana. Para casar a su hija con Jasón, Creonte le recuerda a la protagonista su condición de "nadie": "Medea, ordené que salgas de esta tierra como exiliada, llevándote contigo a tus dos hijos" (vv. 272-273), a lo que Medea le suplica con el fin de tener tiempo para ultimar su venganza: "Permíteme permanecer este solo día y hallar la solución en cuanto adónde partiremos al exilio" (vv. 340-341).

Finalmente, si el nombre propio de Medea refiere a su condición de "nadie", será factible relacionarlo con la categoría de "muerta". Es decir, por su condición de mujer y extranjera, psíquica y socialmente Medea representa a un sujeto "muerto". Al respecto afirma Miller que “(...) el nombre propio designa al sujeto como ya muerto: es el nombre que estará en su tumba. A veces es esencial que el nombre esté sobre la tumba" (2009a, p. 85): ¡Aquí yace Medea, la asesina de sus hijos! dirá la inscripción en su lápida. Por eso, dada su categoría de mujer y forastera, el nombre propio designará a Medea como un 
sujeto "muerto". Con lo expuesto hasta aquí se puede corroborar la importancia del nombre propio en tanto representa el núcleo del ser, en eso que configura la estructura subjetiva. Así, el nombre de pila de Medea contiene en sus "letras y sílabas" los fines que movilizan los distintos tiempos y artilugios de la tragedia, sobre todo aquellos relacionados con su condición de mujer y también de extranjera.

\section{Medea, extranjera: la posición femenina de la "otra" mujer}

El nombre propio es lo menos propio que un sujeto tiene porque es el Otro quien lo nombra, inclusive antes de haber nacido. Antes de la llegada del infante al mundo, los padres ya le han adjudicado un nombre sin que este pueda sancionarlo o recusarlo. Por lo tanto, el sujeto se coloca en posición de extraño, de extranjero, en relación al nombre "propio" que el Otro le ha asignado de antemano. En este sentido, el personaje de Medea representa esta dimensión de "extrañeza", de radical alteridad con respecto a lo que le rodea. Así, se puede partir de una doble antítesis que conecta a Medea con este sentimiento de inquietante extrañeza, a saber, el antagonismo entre lo femenino y lo masculino así como la oposición entre lo griego y lo oriental, antítesis que resulta finalmente en un contraste radical entre ser madre y ser mujer.

Primero, en la cultura griega, el extranjero (xénos) encarnaba la figura del otro desplazado. La calidad de extranjería (xenía) representa el acceso por medio del cual una sociedad acoge en su seno la otredad, aquello radicalmente forastero pero que, sin embargo, le autoriza instaurar su propia identidad. Es decir, el otro es ese extranjero que, viniendo de fuera, se convierte en uno de los suyos: el uno se reconoce por la injerencia del otro que viene a su lugar. Más aún, cabe recalcar que en la cultura clásica existía una distinción entre el extran-

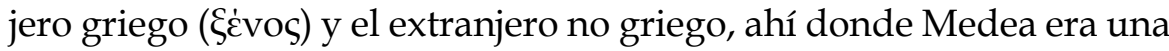
bárbara, una extranjera no griega, procedente del más allá, portadora de unos "conocimientos" ajenos al mundo griego. En fin, esto es lo que Lacan designa con el término de extimidad, el cual es definido como aquello que aun siendo "exterior" es lo más íntimo y personal que cualquier otra cosa propia. Este término está relacionado con la 
propuesta lacaniana sobre la "heteronimia radical" en donde, al nivel de lo inconsciente, el sujeto sufre de una excentricidad fundamental consigo mismo. La extimidad implica "marcar que no hay ninguna complementariedad, ningún ajuste entre el adentro y el afuera, y que hay precisamente un afuera en el interior" (Miller, 2010, p. 31). De hecho, lo éxtimo no es exterior al sujeto, sino lo más íntimo que, desde afuera, retorna en lo real.

En el caso particular de la polis griega, la sociedad estaba regida exclusivamente por varones adultos -ciudadanos representantes de la identidad ateniense- quedando como figuras excluidas, relegadas a la alteridad (héteron), las mujeres, los niños, los esclavos y los extranjeros. Al respecto, Carlos Horacio Bembibre (2001) afirma que en "Medea misma, en esa mujer extranjera, ya se evidencian a doble título aspectos de otredad radical -en su condición de mujer y de extranjera-, una alteridad que nos habita en tanto no es ajena a la constitución de la identidad" (p. 118). Es decir, de alguna manera todos los sujetos guardamos dentro de sí rasgos de esa otredad tan impugnada y rebajada ya que en algún momento nos relacionamos con los demás en posición de "otro".

Esta alteridad -lo éxtimo- también se podría pensar en términos de lo ominoso, de lo Unheimlich freudiano, por cuanto es algo que ciertamente espanta, pero que también convoca y deslumbra, en el sentido de que aunque es radicalmente otro, nos habita. Para Freud, lo ominoso o siniestro es "aquella variedad de lo terrorífico que se remonta a lo consabido de antiguo, a lo familiar desde hace largo tiempo" (1985b, p. 220). En efecto, Medea es esa mujer, hechicera y extranjera que, por amor a Jasón, traiciona a su padre, abandona su patria, asesina a su hermano y, más tarde, mata a sus propios hijos. Asesina, desertora y extranjera en Corinto, Medea adopta esta otredad alienante por amor de su hombre: “(...) y es necesario que la allegada a nuevas costumbres y reglas/sea una adivina, no habiendo aprendido en la casa,/ para que, sobre todo, sea útil al esposo" (vv. 238-240), asienta Medea. O como concluye Bembibre, "la agreste, la extraña, la bruja... La extranjera y la hechicera... Cierta errancia en lo simbólico y cierto contacto con lo real, bien podría situar el deambular femenino de Medea" (2001, p. 121). Todo este recorrido por la radical diferencia nos confirma que Medea se caracteriza por su cualidad de 
"otra", no solo porque es mujer, extranjera y hechicera, sino porque también es "otra" con respecto a Jasón y Glauce. Luego se verá que también es "otra" en relación a su maternidad. En uno u otro caso, Medea siempre será la "otra" mujer.

\section{Medea, no-toda madre: la posición femenina de la "verdadera" mujer}

El psicoanálisis siempre se ha interesado por el asunto de la feminidad, aunque no sin reticencias, ya que para este la mujer es un enigma. Freud refería a ella como el "continente negro" del psicoanálisis, justamente porque de la mujer no se sabe mucho. Por su parte, para Lacan, la feminidad es un atolladero a lo que propone la máxima de que "L/a mujer", como un todo, no existe: "Freud fue el primero en mostrar que no hay esencia de la femineidad. Para Lacan, no existe significante que signifique la femineidad. El inconsciente ignora la diferencia anatómica de los sexos. Hombre, mujer son significantes" (Lachaud, 2000, p. 79). En suma, el hecho de que la feminidad sea un enigma proviene del principio que establece que, en el inconsciente, no existe un significante que logre dar cuenta del sexo femenino, a sabiendas que, para Lacan, ser hombre o ser mujer es una cuestión "lenguajera", más precisamente son esencialmente significantes: el hombre y la mujer no son seres biológicos, sino funciones significantes. En su Seminario 3, Las psicosis, Lacan afirma que:

Hablando estrictamente no hay, diremos, simbolización del sexo de la mujer en cuanto tal. En todos los casos, la simbolización no es la misma, no tiene la misma fuente, el mismo modo de acceso que la simbolización del sexo del hombre. (...) Porque el falo es un símbolo que no tiene correspondiente ni equivalente. Lo que está en juego es una disimetría en el significante. (1984, p. 251).

En sentido estricto, entonces, no se debería hablar de feminidad o de mujeres en general, sino, más bien, de "posiciones femeninas". Si Freud elabora su teoría sobre la feminidad en torno al asunto del "tener" (la mujer no tiene el falo); Lacan, por su parte, lo hace con respecto al "ser", más precisamente con respecto a lo que no es, es decir, 
a su "falta en ser" (la mujer es no-todo). De esta manera la pregunta freudiana de qué quiere una mujer se transforma, con Lacan, en qué es ser una mujer, para lo que siempre habrá un vacío como respuesta. Como se puede notar, la falta no está del lado del tener, sino más bien, del ser, habiendo así diversas formas de responder o de situarse ante tal falta.

Justamente, decir que "La" mujer no existe implica que no hay una sola forma de ser mujer, sino que cada una de ellas elige su manera particular de suplir ese vacío en ser. Por lo tanto, cada mujer podrá descubrir un denuedo singular de suplir el vacío medular, creando su propia "mascarada", con el fin de manifestar su feminidad a su manera singular. Por ejemplo, existen mujeres que revelan su ser femenino siendo "toda madre", mientras hay otras que deciden, consciente o inconscientemente, no serlo; al contrario, siempre habrá algunas que se propongan siendo "no-toda madre". Esto implica que, así como no hay una universalidad de la mujer (L/a mujer no existe), también se podría afirmar que no existe un universal de la madre: "L/a madre no existe", sino que habría que referirse a la singularidad de cada una de ellas: hay tantos tipos de madres como sujetos en el mundo.

La Medea de Eurípides constituye un aspecto peculiar en torno a la posición femenina por cuanto ella representa la distinción radical entre el ser de la madre y el de la mujer. El personaje de Medea manifiesta que tras la maternidad tan valorada por la civilización se antepone la exigencia femenina del amor y la pasión erótica. Después de todo, una madre es, en primer lugar, la mujer de su partenaire. Es decir, tras la maternidad de una mujer siempre se descubre la interpelación femenina del deseo y el amor. La posición femenina de Medea reside en el hecho de que, antes de ser madre, ella reclama un lugar en el deseo de Jasón. Medea nos confirma que la madre es también, y antes que nada, una mujer: “¡Pobre Jasón -exclama Lacan- partido a la conquista del vellocino de oro de la dicha y que no reconoce a Medea!" (Lacan, 2009, p. 724). Lo que Lacan propone es que Jasón es incapaz de reconocer a Medea como una mujer porque se olvida que antes de ser madre ella es alguien que desea ser amada y reconocida por su pareja.

Es en este sentido que Lacan se atreve a decir que Medea representa a la "verdadera mujer"; primero porque madre y mujer son po- 
siciones femeninas que se contraponen, y luego, para indicar que detrás de la "mascarada" de la madre existe una mujer con la exigencia femenina del amor erótico. No reconocer el deseo femenino de Medea es no reconocer que por amor ella se torna en una criminal impúdica, llegando al punto desmedido de asesinar a sus hijos que le son "queridísimos": "Pues a los hijos mataré totalmente,/ a los míos. Nadie será quien me los arrebate;/ después de arruinar la morada toda de Jasón,/ me voy de esta tierra, huyendo del asesinato de/ mis queridísimos hijos" (vv. 790-796), desesperadamente llora la protagonista.

Más allá del filicidio cometido por Medea, que es en sí horrendo e inmoral, se encuentra la verdad de una mujer que es capaz de cualquier cosa cuando su hombre ha quebrantado los juramentos nupciales. La locura del amor femenino de Medea emerge en el justo momento en que ella se enfrenta con el hecho de que ya no es la mujer de Jasón. Es decir, cuando ella se da cuenta de que no es todo para su marido y es incapaz de satisfacerlo. $\mathrm{Y}$ aquí es donde una de las enseñanzas de Lacan podría hacer eco: "amar es dar lo que no se tiene a quien no es" (Lacan, 1999, p. 359), sentencia que implica que en el amor nunca se podrá encontrar la completitud. Esto lleva a relacionar el amor con la condición de la imposibilidad y el no todo. Por lo tanto, el acto siniestro filicida de Medea permite mostrar que en el universo de la sexualidad femenina no basta con que una mujer sea solamente la madre de su producto, puesto que para sostener dicho lugar se requiere de la mediación de un amante que haga de su mujer el objeto de su deseo, reconociéndola.

De hecho, de acuerdo con la tesis freudiana, la mujer busca en su partenaire aquello que le podría completar su falta en ser, siendo la maternidad una salida conveniente para suplir dicha falta. En su Seminario 20, Lacan (1981) asienta a propósito que:

la mujer no entra en función en la relación sexual sino como madre (...) Para este goce de ser no-toda, es decir que la hace en alguna parte ausente de sí misma, ausente en tanto sujeto, la mujer encontrará el tapón de ese a que será su hijo (p. 47).

Es decir, con la maternidad la mujer ciertamente podría encontrar cierta plenitud del ser. No obstante, al considerar la feminidad desde el binomio mujer-madre se obvia el hecho de que la mujer usualmen- 
te se coloca en relación al hombre en una condición de "servidumbre enamorada", en el sentido de que es por la vía del amor donde la mujer también puede lograr algo de completud en su ser. Es por esta razón que la pérdida del amor de un hombre funciona en la sexualidad femenina como angustia de castración, es decir, como falta en ser. $\mathrm{Al}$ menos esto es lo que nos enseña Freud con su teoría enigmática sobre la feminidad.

A diferencia del arrebato de Clitemnestra que mata a su marido Agamenón, Medea, por su parte, decide "acabar" con aquello que es lo más preciado para Jasón, embistiéndolo de un modo que lo desagarre al extremo -más que matarlo físicamente, lo aniquila al nivel de la psique y el deseo- asesinando a sus propios hijos: matando a sus retoños, Jasón "sería ofendido terriblemente" (v. 817). Es importante acotar en este punto que Medea mata sus hijos no por falta de amor hacia ellos, sino en respuesta, por medio de un pasaje al acto, a la falta de reconocimiento por parte de Jasón. De hecho, asesinar a sus hijos no es un acto impulsivo sino un proceso lleno de dudas y aflicción:

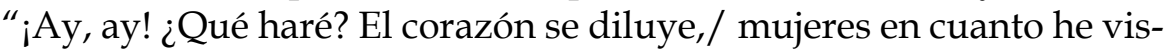
to la mirada brillante de mis hijos./ No podría. Adiós a las resoluciones/ de antes. Llevaré a mis niños desde esta tierra" (vv. 1042-1046). Finalmente, Medea decide a matar a sus hijos, no por falta de amor a ellos, sino para ofender a Jasón "terriblemente": "No te acobardes ni te acuerdes de tus hijos/ que te son queridísimos, a quienes has parido,/ sino durante este breve día olvídate de tus niños/ y después emite el lamento fúnebre. Pues aunque los mates,/ igualmente fueron queridos, y yo, una mujer desafortunada" (vv. 1246-1250), llora la protagonista. El pasaje al acto infanticida constituye una maniobra del orden de lo real que le restituye a Medea su condición de mujer, pero que también funge como el castigo máximo que le puede proporcionar a Jasón quien era un sujeto ambicioso que se vanagloriaba de su alcurnia, de su inscripción en la casa real de Creonte y de esos hijos que iban a continuar su linaje familiar. Al aniquilar a sus hijos, Medea hace que Jasón quede en total desamparo, destinado a una vejez adusta, amargada y solitaria.

Tanto la maternidad como la feminidad propias de Medea constituyen un pasaje al acto imposible de imaginarizar y de simbolizar: no hay palabras (lo simbólico) ni imágenes (lo imaginario) que logren 
dar cuenta del arrebato que siente nuestra protagonista cuando es traicionada por Jasón. Es justamente en este punto que Medea se encuentra muy cerca del das Ding freudiano, ese objeto inasible perdido en un pasado anterior mítico: “(...) un objeto como este es simultáneamente el primer objeto-satisfacción y el primer objeto hostil, así como el único poder auxiliador" (Freud, 1985a/1895, p. 373). En el caso de Medea, la madre -mujer muerta- cuya mascarada revela das Ding, se contrapone a la mujer viva, la cual llegar a "engañar al sujeto, en el punto mismo de das Ding" (Lacan, 1988, p. 123), argumenta Lacan en su Seminario 7 sobre la ética, afirmación que revela su condición de no-toda madre. Si para Freud este imposible de soportar refiere a la categoría de la Cosa, del das Ding, para Lacan el arrebato de Medea se puede localizar en el orden de lo real, registro perteneciente a lo imposible e indecible. El caso de Medea trata de lo insoportable del amor cuando no se tiene límite ni en lo imaginario ni lo simbólico. Isidoro Vegh (2001) asienta que "en la tragedia se trata de los Real del amor de una madre, he ahí el horror que Medea nos acerca, horror de cualquier amor cuando es sólo amor fundado en lo Real" (p. 149). Este horror de "amor real" se hilvana cuando el lector-espectador se coloca en presencia de una madre que asesina a sus hijos, de una notoda madre, cuando, al contrario, nuestra civilización no hace más que exaltar el amor materno.

Desde esta perspectiva freudiana es que se podría analizar la obra de Eurípides en el sentido de que tras la maternidad de Medea se perfila una servidumbre enamorada: es decir, la que es madre es, antes que nada, la esposa celosa de su marido. En el decir de Freud, se puede concluir que si Jasón puede desear en otro lugar es porque Medea está castrada, a saber, que a ella le falta algo para completarlo a él. Este falo, en tanto elemento que completa a su pareja, y que ella pretendía concederle pero que Jasón no le restituye, era fundamental identificarlo en él, sin lo cual se siente dispensada de dicha función fálica. Al respecto afirma Dominique Poissonnier (1999) que "al abandonar la organización imaginaria que la ligaba a Jasón y que tendía a probar que, para la mujer y a causa de su propio poderío, la castración está derrotada para siempre, Medea pretende revelar en cierto modo su verdadero rostro" (p. 164), que es el de una mujer completa y sin falta en donde coloca a sus hijos en sustitutos metonímicos del 
falo arrebatado. De aquí que muchos estudiosos adviertan que Medea está loca porque sitúa a sus hijos en el lugar del falo castrado reafirmando así el amor narcisista que siente por su propia imagen. De hecho, es cuando Medea se topa con la imposibilidad de nombrar a Jasón como su esposo que ella se presenta con un temperamento melancólico debido a la pérdida de dicho amor. Hacia el inicio de la obra, la nodriza describe el talante de Medea en estos términos: "Yace sin comida, tras disponer el cuerpo para los dolores/ consumiendo el tiempo todo entre lágrimas,/ después de que se contempló injuriada por el marido,/ ni levantando la mirada ni apartando de la tierra el rostro (...)" (vv. 24-28). Es decir, Medea se siente abatida, dolorosamente enloquecida por la traición amorosa de Jasón que le ha marcado en lo más profundo su ser. En realidad, lo que anula y extermina en sus hijos, "lo que tacha en una escritura de sangre, es el pene imaginario: como se le escapa y falta en sí en su imagen, no puede admitir su persistencia en otra parte" (p. 165), concluye Poissonnier.

Es así que Eurípides nos muestra a una mujer excluida, doblemente extranjera, a una esposa despreciada quien arde en el fuego de un odio aprensivo y unos celos enloquecedores que fungen como imágenes de la herida narcisista infringida por la traición de Jasón. Medea se encuentra en una posición de mujer afectada en su narcisismo, la cual sufre de unos celos filicidas, "celosgoce" (jalouissance), según lo propone Lacan (1981, p. 121), para lo que Dominique Poissonnier (1999) aclara: “(...) se opone en ella a la posición de madre, al extremo de suplantarla. Al matar a sus hijos, ataca a la vez al hombre y anula su posición materna: anulación mágica, con 'exceso' real, pero sin retorno posible a la Virgo" (p. 167). Es por ello que el asunto de los celos, tal y como los concibe el psicoanálisis, es primordial en el análisis de la tragedia de Eurípides.

En la trayectoria de los celos, el celoso o la celosa desea al otro como un todo para sí -aquí el adjetivo indefinido "todo" significa completo, sin mancha, es decir, no castrado-, lo cual, como se previno, es hacer de él una completud avasalladora al punto de convertirlo en la Cosa, das Ding. Tal tipo de amor, muy cercano a la estructura psicótica, permite que este se convierta en odio; más precisamente, que por lo celos, el amor que se siente por la pareja se transforme en odio aniquilador: "odioamoramiento" (hainamoration), diría Lacan 
en su Seminario 20 (1981, p. 110). De hecho, en el verdadero celoso, la duda gravita en torno a una certeza, a una absoluta convicción que toca lo real, eso que el mismo Lacan definió como lo imposible e inasible, pero que, sin embargo, no cesa de no escribirse. Llegado a este punto, los celos espolean lo pulsional haciendo que el amor por el otro se torne en odio puro. Al respecto asegura Lachaud (2000) que "Medea matará a su rival enceguecida por este velo envenenado del amor celoso, velo que la hizo de ella una mujer, la de Jasón" (p. 84). En suma, Medea, esa celosa impúdica, es aquella incapaz de aceptar ni sobrellevar la satisfacción, el goce o la felicidad de Jasón. Medea, en tanto mortalmente celosa, "busca y quiere todo. Busca privar al otro de aquello con lo que goza. El celoso tiende hacia el narcisismo total y absoluto. Sin falla, niega el significante de la falta en el Otro $-\mathrm{S}(\mathrm{A} /)^{\prime \prime}$ (Lachaud, 2000, p. 110).

De hecho, para Freud, en la sujeción amorosa de una mujer se puede entrever una renuncia total por parte de esta a su objeto de amor, por cuanto el objeto (Jasón), por así decirlo, ha devorado el yo de Medea hasta el punto que “(...) en la ceguera del amor, uno se convierte en criminal sin remordimientos" (1985c/1921, p. 107), sostiene Freud en su "Psicología de la masas y análisis del yo". En nombre del amor, Medea se convierte en una criminal sin contrición, no solo por asesinar a sus propios hijos, sino también a lo largo del transcurso de obra, a saber, cuando descuartiza a su hermano, traiciona a su padre o mata a Glauce para vengarse de Jasón. Al respecto, afirma Roxana Hidalgo (2010) que "la agresión desencadenada por la decepción que el abandono del objeto amoroso provoca es dirigida hacia aquellos otros asociados directa o indirectamente con el agravio (como la nueva esposa de Jasón, el rey, Jasón y los niños)" (p. 224). En suma, de acuerdo con la versión freudiana, Medea sintetiza el hecho de que tras la maternidad tan estimada por la cultura se encuentra la sujeción amorosa de una mujer hacia su partenaire. En el inicio de la tragedia, la Nodriza exclama: “y Medea, la desgraciada, habiendo sido deshonrada,/ grita los juramentos, clama/ la fe mayor de la diestra y a los dioses llama como testigos/ del tipo de recompensa que obtiene de Jasón" (vv. 20-23). Lo que la nodriza presagia es que hay un sujeto que ha sido víctima de un terrible agravio, ultraje del lecho, en donde 
Medea ha sido humillada en el núcleo de su feminidad "por un hombre que ahora la tiene después de deshonrarla" (v. 33).

A diferencia de Freud, Lacan, por su parte, sostiene que las categorías de madre y de mujer de ninguna manera se superponen en el sentido de que tras toda madre existe siempre una mujer primero; "más precisamente, la madre es una mujer para un hombre" (2013, p. 359), arguye Mónica Larrahondo al respecto. Es decir, la maternidad no colma el ser de una mujer puesto que toda madre es primeramente esa mujer que busca ser reconocida por su partenaire. Con respecto al tema de los celos, Assoun (2012) asienta, a propósito, que:

Medea es celosa -en el sentido originario-, del honor de su feminidad y su acto extremo [de asesinar a sus propios hijos] pasa a significar, contra el hombre que la ha negado, el rechazo sangriento a verse encarnecida, lo que, al decir de Lacan, la convierte en 'la verdadera mujer' (p. 134).

Ciertamente aquí de ninguna manera se intenta sugerir que el acto criminal de Medea corresponda al de una "verdadera mujer", pues reducir la motivación del filicidio a los celos matrimoniales sería empobrecer en extremo un personaje tan complejo y rico. Es más, una de dichas motivaciones del acto funesto es la de liberar ella misma a sus hijos de un destino que considera indigno de ellos; la cual, además, no es excluyente de la reparación que por la ofensa ella ha sido objeto, recordando que ella es una princesa, nieta de un dios y a la que Jasón debe todo lo que ha llegado a ser. Por eso, dicho acto filicida no es que sea el de una "verdadera mujer". Más bien, lo que tiene de "verdadero" es que en la mujer puede existir un más allá de la maternidad, con lo cual nuestra protagonista se convierte en solidaria de esa posición femenina de la no-toda madre. Siguiendo la propuesta lacaniana, entonces, se puede aseverar que el acto de Medea no está circunscrito a una lógica fálica -continente del tener-, sino, muy al contrario, a una lógica del no-todo. En Medea predomina su goce femenino más que su deseo maternal, punto donde ella es capaz de despojarse del todo "tener" con el fin de "ser" no-toda madre. En ese sentido, la mujer se convierte en "extravío". Lacan (1999), al respecto indica que "(...) una feminidad, una verdadera feminidad, siempre tiene hasta cierto punto una dimensión de coartada. Las verdaderas 
mujeres, eso siempre tiene algo de extravío [quelque chose d'égaré]" (p. 201).

Lacan no solamente propone la no-universalidad de la mujer (L/a mujer no existe), porque hay que tomarlas una por una, sino que también llega a aseverar que existen las "verdaderas mujeres". En su escrito sobre André Gide, sostiene que tanto la mujer de este -Madeleine- como Medea encarnan la figura de "una verdadera mujer en su integridad de mujer" (2009, p. 723) por cuanto ambas perpetran un acto absoluto en donde siempre están resueltas a sacrificar el "tener" en nombre del "ser". En el caso de Medea, se trata de una mujer que fue vilmente traicionada en el reconocimiento de ser todo para el otro y que, para defenderse y descompletarlo, no le quedó más remedio que escindirse ella misma cercenando lo más preciado para ella -sus queridísimos hijos.

Entonces, en stricto sensu, una "verdadera mujer" es aquella que logra construir una distancia subjetiva respecto a su posición de ser toda-madre. En "De mujeres y semblantes", Jacques-Alain Miller (2009b) sostiene que “(...) ser una madre, ser la madre de sus hijos, es para una mujer querer hacerse existir como La. Hacerse existir como La madre es hacerse existir como La mujer en cuanto tiene" (p. 101). Ahora bien, sobre la "verdadera mujer" solamente se puede decir de una en una, o sea, no todas las mujeres tienen la capacidad de devenir en verdaderas mujeres. Y segundo, esas pocas "verdaderas" medeas llegan a serlo solamente una vez: "esto se articula al sacrificio de los bienes, al sacrificio del todo tener, y quizás por eso ese grito lo merece una mujer precisamente cuando ha consentido con la modalidad propia de su castración" (Ídem), es decir, las pocas verdaderas mujeres son aquellas capaces de inmolar su todo tener por el ser.

Finalmente, es preciso aclarar que para Lacan el acto filicida de Medea no es que sea el de una verdadera mujer, pero ciertamente tiene su estructura. La constitución de dicho acto puntualiza la privación de lo que tiene de más precioso y preciado en ella para abrir en su partenaire el agujero que nunca se podrá saturar. Concluye Miller (2009b) diciendo que "una verdadera mujer explora una zona desconocida, ultrapasa los límites, y si Medea nos da un ejemplo de lo que hay de extraviado en una verdadera mujer, es porque explora una 
región sin marcas, más allá de las fronteras" (p. 102). En fin, el asesinato infanticida de Medea constituye un pasaje al acto en lo real, una emergencia de lo absoluto, en donde ella ha sido capaz de dirigirse, dolorosamente, al no tener, realizándose en ese no tener, justamente, más del lado de la mujer, como no-toda madre. Amándose más a sí misma, colocada más del lado del amor que de la maternidad, Medea advierte "que toda persona se ama más a sí misma que al vecino" (v. 86).

\section{Conclusión}

La Medea de Eurípides es la tragedia de la feminidad absoluta. Ubicada más allá de la maternidad, ella se convierte en el paradigma de la mujer que sacrifica el tener (sus hijos) por el ser (mujer). Y no es que en ella no opere la función de la maternidad, sino que se coloca en un más allá de eso. Ciertamente, sus hijos le resultan "queridísimos", más no obstante son arrastrados por su odio y celos desmesurados: ella los ama, pero es ineludible que se presenta ante ellos como madre en falta. La protagonista se descubre como esa mujer que, avasallada por la pasión amorosa, exhibe sin tapujos su privación y falta en ser matando aquello que le es más preciado a ella, pero, sobre todo, a Jasón. Arrebatándole a sus hijos, Medea hace que su marido quede barrado, escindido en lo más profundo de su ser, reducido a eso que nunca será: ni padre, ni esposo, ni rey, ni siquiera deudo. En todo caso, lo que se desprende de una posible lectura lacaniana de Medea es que no todas las mujeres pueden declararse tal por la vía de la maternidad al entendido de que toda madre es, antes que nada, la mujer de su partenaire. O como lo espeta la misma Medea: "pero somos como somos, no diré algo malo, solo mujeres" (vv. 889-890).

\section{Referencias}

Assoun, P.-L. (2012). Lecciones psicoanalíticas sobre los celos. Buenos Aires, Argentina: Nueva Visión. 
Bembibre, C. H. (2001). Medea, nuestra terrible extranjera. En I. Vegh, El prójimo. Enlaces y desenlaces del goce (pp. 114-131). Buenos Aires, Argentina: Paidós.

Borges, J. L. (2015). El otro, el mismo. En Obra poética (pp. 161-264). Buenos Aires, Argentina: Emecé.

Eurípides. (2010). Medea. (E. Rodríguez Cidre, Ed.). Buenos Aires, Argentina: Losada.

Freud, S. (1985a/1895). Proyecto de psicología. En J. Strachey (Ed.), Obras completas (J. L. Etcheverry, Trad., Vol. I, pp. 323-446). Buenos Aires, Argentina: Amorrortu.

Freud, S. (1985b/1919). Lo ominoso. En J. Strachey (Ed.), Obras completas (J. L. Etcheverry, Trad., Vol. XVII, pp. 215-252). Buenos Aires, Argentina: Amorrortu.

Freud, S. (1985c/1921). Psicología de las masas y análisis del yo. En J. Strachey (Ed.), Obras completas (J. L. Etcheverry, Trad., Vol. XVIII, pp. 63136). Buenos Aires, Argentina: Amorrortu.

Hidalgo-Xirinachs, R. (2010). La Medea de Eurípides. Hacia un psicoanálisis de la agresión femenina y la autonomía. San José, Costa Rica: Editorial de la Universidad de Costa Rica.

Lacan, J. (1961-1962). Seminario 9: La identificación. (Inédito). Recuperado de la base documental Folio View 4.2.

Lacan, J. (1981). El seminario de Jacques Lacan, Libro 20: Aún. Buenos Aires, Argentina: Paidós.

Lacan, J. (1984). El seminario de Jacques Lacan, Libro 3: Las psicosis. Buenos Aires, Argentina: Paidós.

Lacan, J. (1988). El seminario de Jacques Lacan, Libro 7: La ética del psicoanálisis. Buenos Aires, Argentina: Paidós.

Lacan, J. (1999). El seminario de Jacques Lacan, Libro 5: Las formaciones del inconsciente. Buenos Aires, Argentina: Paidós.

Lacan, J. (2009). Juventud de Gide o la letra y el deseo. En Escritos 2 (pp. 703726). (3ra edición). México: Siglo Veintiuno Editores.

Lachaud, D. (2000). Celos. Un estudio psicoanalítico de su diversidad. Buenos Aires, Argentina: Nueva Visión.

Larrahondo, M. (2013). ¿Existe una "verdadera mujer"? Una lectura de la posición femenina a partir de la alusión que Lacan realiza de Medea como una "verdadera mujer". En V Congreso Internacional de Investigación y Práctica Profesional en Psicología de la Universidad de Buenos Aires, Facultad de Psicología de la Universidad de Buenos Aires (UBA), Buenos Aires-Argentina. 
Miller, J-A. (2009a). Comentario del seminario inexistente. En Conferencias Porteñas 2 (pp. 73-96). Buenos Aires, Argentina: Paidós.

Miller, J-A. (2009b). De mujeres y semblantes. En Conferencias Porteñas 2 (pp. 97-112). Buenos Aires: Paidós.

Miller, J-A. (2010). Extimidad. Buenos Aires, Argentina: Paidós.

Peinado-Vázquez, R. V. (2011). Razones y sin razones del infanticidio de Medea. En Nómadas. Revista Crítica de Ciencias Sociales y Jurídicas, 32(4), s.p.

Platón. (2017/1966). Crátilo o de la exactitud de los nombres. Carolina del Sur, EE.UU.: CreateSpace Independent.

Poissonnier, D. (1999). La pulsión de muerte. De Freud a Lacan. Buenos Aires, Argentina: Nueva Visión.

Tesone, J. E. (2009). En las huellas del nombre propio. Lo que los otros inscriben en nosotros. Buenos Aires, Argentina: Letra Viva.

Vegh, I. (2001). El prójimo. Enlaces y desenlaces del goce. Buenos Aires, Argentina: Paidós. 